\title{
Ensino Jurídico na América Latina ${ }^{1}$
}

\section{Augusto Jaeger Junior ${ }^{2}$}

\section{A mobilidade sem fronteiras buscada pelo Processo de Bolonha}

Segundo as informações que chegam à América Latina, o Processo de Bolonha, desenvolvido na Europa desde 1999, busca facilitar a mobilidade dos possuidores de títulos universitários e profissionais, na atual sociedade de necessidades cambiantes, para com isso permitir perspectivas de empregos presentes e futuras. As propostas caracterizam-se pela harmonização de sistemas e estruturas educacionais nacionais.

O Processo de Bolonha prevê a adoção de um sistema com graus acadêmicos de fácil equivalência, através da implantação de um suplemento do diploma, que é um documento apenso ao certificado original cujo propósito é melhorar a transparência internacional, de forma a facilitar a mobilidade e a empregabilidade dos estudantes, diplomados, docentes e investigadores promovendo o reconhecimento acadêmico e profissional das qualificações. Prevê também a adoção de um sistema baseado em dois níveis, graduação e pós-graduação, de um sistema de créditos para a mobilidade estudantil, o exercício da mobilidade, a cooperação européia na avaliação de qualidade a o alcance de um espaço europeu comum de educação superior ${ }^{3}$.

$O$ Processo de Bolonha significa pesquisas sem fronteiras, poder ensinar e estudar; diplomar-se com um título reconhecível em todos os lados e que possa ser utilizado, para fins profissionais, em toda a Europa.

Por isso ele é entendido como um elemento indispensável à cidadania européia, capaz de oferecer aos seus cidadãos as aptidões necessárias para enfrentar os desafios do novo milênio, em paralelo com a consciência de partilha dos valores e de pertencimento a um espaço social e cultural comum.

\footnotetext{
Este artigo consolida a conferência proferida no congresso Junstenausbildung in Europa: zwischen Tradition und Reform, ocorrido em Trier, Alemanha, de 23 a 25 de novembro de 2007, a convite dos Profs. Drs. Christian Baidus, de Heidelberg, Thomas Rüfner, de Trier, e Thomas Finkenauer, de Tübingen, aos quais agradeço, e financiado pela Fritz Thyssen Stiftung für Wissenschaftsförderung. Foi publicado originalmente sob o título Juristenausbildung in Lateinamerika. In: BALDUS, Christian; FINKENAUER, Thomas, RÜFNER, Thomas (Hrsg.) Juristenausbildung in Europa zuischen Tradition und Reform. Tübingen: Mohr Siebeck, 2008 pp. 279-305. O autor também agradece o apoio do Projeto Conjunto de Pesquisa, Cooperação Científica e de Intercâmbio entre o Departamento de Direito Público e Filosofia do Direito da UFRGS e a Academia Juris Internationalis da Justus-Liebig-Universität Giessen, Alemanha, financiado pela CAPES e pelo DAAD, e as informações recebidas de juristas latino-americanos, em especial de Eliseu Mânica, Nadia de Araújo, Eduardo Capellari, Loussia Penha Musse Felix, do Brasil, Indra Rojas Solano, da Costa Rica, Lucy Arraya, de Santo Domingo, Eugênio Hernández-Bretón, da Venezuela, Michel Levi, do Equador, e Lucas Liendro Kapustik e Mario Edgardo Rojas, da Argentina

2 Professor de Direito Internacional, Direito Comunitário e Direito das Relações Internacionais na Faculdade de Direito da Universidade Federal do Rio Grande do Sul, Porto Alegre, Brasil, e professor convidado do curso de Adrninistração Estratégica de Negócios na Universidade Nacional de Misiones, Posadas, República Argentina.

3 MOROSINI, Marilia Costa (editora). Enciclopédia de Pedagogia Universitária: glossário. Brasília: Instituto Nacional de Estudos e Pesquisas Educacionais Anísio Teixeira, 2006. v. 2. p. 116-130.
} 
Em maio de 2007 encontraram-se, em Londres, os 46 Ministros de Educação para a Quarta Conferência de Acompanhamento sobre Bolonha e realizaram um balanço positivo. Foi prevista a continuidade do Processo. A Mobilidade é uma questão central. Os sistemas de reconhecimento acadêmico possuem muita relevância no contexto da mobilidade mundial ${ }^{4}$.

Evidentemente que há problemas e preocupações que acompanham o Processo. As carreiras muito estreitas de bacharelados de três anos deixam pouco espaço para experiências que possam ser feitas no exterior. Ademais, uma estadia no exterior é, para a maioria, muito cara, os programas nacionais de incentivo são limitados e as competências em língua estrangeira dos participantes são, normalmente, insuficientes.

Como uma resposta das universidades ao desafio proposto em Bolonha de criar e consolidar um espaço europeu de educação superior e de contribuir para a mobilidade dos estudantes e profissionais, a União Européia gerou o Projeto Tuning Europa, em 2001, envolvendo a participação de 135 universidades. Ele tem por objetivo sintonizar as estruturas educativas da Europa.

Essas experiências do Espaço Europeu de Educação Superior se tornaram conhecidas na América Latina. A necessidade de compatibilização da educação superior se mostrou não ser uma aspiração exclusiva da Europa ${ }^{5}$.

$\mathrm{Na}$ América Latina, acreditava-se haver uma crescente demanda de compatibilização dos programas de formação entre universidades para o favorecimento da mobilidade e do intercâmbio de estudantes e professores. $O$ reconhecimento automático de títulos, perspectivas de empregos e manutenção dos mesmos, mais a atratividade dos custos de uma pós-graduação em todas as áreas têm levado milhares de brasileiros fronteiriços aos países vizinhos, por exemplo, em busca de serviços educacionais. Então, não é de se espantar a simpatia que colhem essas idéias.

As universidades européias tinham interesse em conhecer quais seriam as conclusões a que chegariam as suas correspondentes latino-americanas. Existia uma grande expectativa em saber o grau de correlação que teriam os resultados obtidos na Europa com aqueles a serem obtidos na América Latina.

A idéia de criar algo similar surgiu na IV Reunião de Seguimento do Espaço Comum de Ensino Superior da União Européia, América Latina e Caribe, celebrada em outubro de 2002, em Córdoba, Espanha. Lá, os representantes latino-americanos, após escutarem a apresentação dos resultados do Projeto Tuning Europa, propuseram um projeto

4 GONZÁLES, Julia; WAGENAAR, Robert; BENEITONE, Pablo. Tuning-América Latina: un Proyecto de las Universidades Revista Iberoamericana de Educación, n. 35, may./ago. 2004, p. 154.

5 GONZÁLES, Julia; WAGENAAR, Robert; BENEITONE, Pablo. Tuning-América Latina: un Proyecto de las Universidades. Revista Iberoamericana de Educación, n. 35, a. 2004, p. 153 
na América Latina. Ele foi apresentado à Comissão Européia em outubro de $2003^{6}$. Ele é subvencionado pela Comissão Européia e por ministérios de educação latino-americanos, dentro do marco do Projeto Alfa. A Universidade de Deusto, em Bilbao, foi encarregada para a execução das tarefas.

Ante a esses fatos, eu me proponho a responder as seguintes perguntas: Há experiências na América Latina como a do Processo de Bolonha? Elas serviriam ao direito? Quanto a essa ciência, porque não houve experiências ou porque as experiências que a América Latina conheceu não tiveram sucesso?

\section{Projeto Tuning América Latina}

O Projeto Tuning América Latina iniciou em 2004 e contou com 19 países, que juntos possuem uma população de mais de quinhentos milhões de pessoas, dentre os quais 15 milhões de estudantes no sistema universitário, e com 190 universidades latino-americanas. Ele surge em um contexto de intensa reflexão sobre a educação superior e de busca por uma informação confiável e objetiva sobre a oferta de educação no Continente ${ }^{7}$.

Como na Europa, através de perspectivas que possam facilitar a mobilidade dos possuidores de títulos universitários e profissionais, a versão latino-americana do projeto tem como meta impulsionar consensos sobre a forma de entender os títulos acadêmicos, a partir das competências genéricas e específicas que os seus possuidores sejam capazes de realizar. O ponto de partida do Projeto é a busca de pontos comuns de referência centrados em competências e destrezas baseadas sempre no conhecimento ${ }^{8}$.

Uma definição sobre competência não é facilmente encontrada. Tuning Europa apresenta a seguinte, que tem sido uma base para o projeto latino-americano: as competências representam uma combinação dinâmica de conhecimento, compreensão, capacidades e habilidades. Fomentar as competências é o objeto dos programas educativos. As competências se formam em várias unidades do curso e são avaliadas em diferentes etapas. Podem estar divididas em competências relacionadas com uma área de conhecimento (específicas de um campo de estudo) e competências genéricas (comuns para diferentes cursos) ${ }^{9}$.

6 GONZÁLES, Julia; WAGENAAR, Robert; BENEITONE, Pablo. Tuning-América Latina: un Proyecto de las Universidades. Revista Iberoamericana de Educación, n. 35, a. 2004, p. 155

7 Sobre as características dos sistemas de educação superior na América Latina, sobre os impactos da giobalização nas universidades e a intemalização das mesmas ver as obras MOROSINI, Marilia Costa (Org.). Mercosul/Mercosur políticas e ações universitárias. Porto Alegre: Editora da Universidade, 1998. 251 p; MOROSINI, Marilia Costa; LEITE, Denise (Orgs.). Universidade eintegração no Cone Sul. Porto Alegre: Editora da Universidade, 1992.135 p; MOROSINI, Marília Costa (Org.). Universidade no Mercosul: condicionantes e desafios. São Paulo: Cortez, 1994. 308 p.; e MOROSINI, Marília Costa. Estado do conhecimento sobre intemalização da educação superior: conceitos e práticas. Educar em Revista. Curitiba: Editora UFPR, jul./dez. 2006. p. 107-124

8 GONZÁLES, Julia; WAGENAAR, Robert, BENEITONE, Pablo. Tuning-América Latina: un Proyecto de las Universidades. Revista Iberoamericana de Educación, n. 35, a. 2004, p. 156

9 REFLEXIONES y Perspectivas de la Educación Superior en América Latina: Informe Final - Proyecto Tuning América Latina (2004-2007). 432p.

Disponível em: http://tuning.unideusto.org/tuningal/index.php?option=com_docman\&task=view_category\&catid= 22\&Itemid $=191 \&$ order $=$ dmdate_published\&ascdesc $=$ ASC. Acesso em 15.11.2007. 
As competências são descritas como referências para o desenho e a avaliação dos planos de estudos e não como "camisas de força". As referências garantem flexibilidade e autonomia na construção dos planos de estudo e proporcionam uma "linguagem compartida" com aquele que descrever os seus objetivos. Assim, os conhecimentos e habilidades mais importantes que um estudante tenha que adquirir durante o processo de aprendizagem devem determinar os conteúdos do programa de estudo.

As competências representam uma combinação de atributos em relação ao conhecer e compreender (conhecimento teórico de um campo acadêmico), ao saber como atuar (aplicação prática e operativa da base do conhecimento) e ao saber como ser (valores como parte integrante da forma de perceber os outros e viver em um contexto) que possa ser gerada em qualquer titulação e que seja considerada importante por certos grupos sociais.

O Projeto Tuning informa que a opção por um ensino baseado no conceito de competência pode trazer as seguintes vantagens para a educação: identificar perfis profissionais e acadêmicos das titulações e programas de estudos; desenvolver um novo paradigma de educação, primordialmente centrada no estudante e na necessidade de gestão de conhecimento; responder as crescentes demandas de uma sociedade de aprendizagem permanente e de uma maior flexibilidade na organização da aprendizagem; contribuir para a busca de níveis mais elevados de empregabilidade e cidadania; propiciar um impulso para a construção e consolidação de um Espaço de Educação Superior; consolidar programas que fomentem uma intensa mobilidade de estudantes e professores; e estimular acordos para a definição de uma linguagem comum, que facilite o intercâmbio e o diálogo entre os diferentes grupos interessados.

$O$ interesse no desenvolvimento de competências concorda com o enfoque de uma educação centrada no estudante e em sua capacidade de aprender, exigindo mais compromisso dele, já que é ele mesmo que deve desenvolver as competências.

De fato, um dos paradigmas da educação atual é que o centro do processo de ensino-aprendizagem deixa de ser o professor e passa a ser o estudante. Torna-se necessário que o docente ceda o cenário, o protagonismo, a palavra e o tempo aos estudantes. Assim, a educação centrada no ensino passa a ser sustentada na aprendizagem. O estudante passa a ter uma participação, ativa na construção da sua própria aprendizagem, se convertendo, assim, o professor em um grande facilitador que oferta aos estudantes os recursos de informação, métodos, ferramentas, cria ambientes e os acompanha ao longo de todo o processo, elevando a sua motivação pelo aprender e compreender a utilidade da aprendizagem. A idéia é que as universidades formem os seus estudantes com a perspectiva que a aprendizagem seja uma tarefa vitalícia, para uma carreira produtiva e para a cidadania.

\section{Projeto Tuning América Latina e Ensino Jurídico}

O Grupo de Estudo do Projeto Tuning para o direito foi constituído em fevereiro de 2006. Ele também tinha como ponto de partida avançar em um desenvolvimento 
de titulações comparáveis e compreensíveis, facilitando, com isso, os processos de reconhecimento de títulos e permitindo a mobilidade de estudantes, profissionais e acadêmicos.

Vale uma referência à menção sempre presente nos comunicados oficiais de que o Projeto entende ser fundamental a proteção da diversidade da educação latinoamericana e que sob nenhum aspecto ele busca restringir a independência dos especialistas ou prejudicar as autoridades. Tampouco desenvolver uma espécie de currículo único ${ }^{10}$. Assim também é o seu lema: harmonização das estruturas e programas educativos respeitando sua diversidade e autonomia.

Com essa atitude, o Projeto se mostrava conhecedor da importância de ver o ensino do direito em um contexto complexo, com realidades particulares da América Latina, como por exemplo: o retorno à democracia ocorrido nos anos 80 , com diferentes graus de desenvolvimento e profundidade; o reconhecimento dos direitos humanos como objeto de um sistema jurídico; a crise do Estado de bem-estar; os graves problemas nos processos de integração entre os Estados; os problemas derivados do grau de desenvolvimento econômico dos Estados, a problemática das migrações internas; e as dificuldades relativas à preservação do meio ambiente.

De fato, o direito é um dos cursos mais antigos no espaço educacional latinoamericano. Ele conta com uma larga história quanto à organização do seu currículo, metodologia de ensino, objetivos de aprendizagem e formação de docentes. Isso, em muitas situações, poderia se contrapor a um modelo de formação por competências.

Permitam-me dirigir-me aos resultados da busca por informações quanto à formação em direito, ao nível de graduação em direito, ao mapa de profissões, ao sistema de créditos e às competências específicas da disciplina. Eles foram colhidos na publicação oficial Reflexões e Perspectivas da Educação Superior na América Latina, Informe Final do Projeto Tuning América Latina (2004-2007), assinada pelas Universidades de Deusto e de Groningen.

\subsection{Formação em direito}

A dogmática jurídica é a matriz teórica dominante na maior parte dos cursos, com ênfase metodológica na transmissão de conteúdơs tẹóricos por parte do docente e a absorção desses pelos estudantes. Os processos de aprendizagem são fundados em uma metodologia de assimilação não-crítica de proposições teóricas ou memorização de normas jurídicas.

Em alguns países, são conhecidas iniciativas de reformas de currículos, com a adoção de propostas de flexibilização, ênfase em formação prática, retorno a uma formação mais crítica, com o estudo das relações entre o direito e as outras ciências sociais e uma maior participação dos estudantes no processo de ensino e aprendizagem.

10 GONZÁLES, Julia; WAGENAAR, Robert; BENEITONE, Pablo. Tuning-América Latina: un Proyecto de las Universidades. Revista Iberoamericana de Educación, 11. 35, a. 2004, p. 156. 


\subsection{Nivel do curso de graduação em direito}

O curso para a obtenção de um título de graduação tem uma duração média de cinco anos. Os concluintes obtêm, na maior parte dos países, o título de advogado. $\mathrm{O}$ título de bacharel em direito é o outorgado pelo Brasil, país em que, para o exercício da profissão de advogado, se há que prestar uma prova perante a Ordem dos Advogados do Brasil. A denominação de licenciado em Ciências Jurídicas é utilizada em El Salvador e na Nicarágua. O Chile outorga um título de licenciado em Ciências Jurídicas e Sociais, sendo nesse país o título de advogado outorgado pela Corte Suprema.

O continente também conhece as titulações mais avançadas, como as especializações, mestrados e doutorados, o que demonstra o seu encaminhamento para um sistema de educação continuada. Nesse sentido, a formação em uma pósgraduação para o exercício da docência está sendo progressivamente requerida e constitui um critério de qualidade em muitos países.

\subsection{Mapa de profissões}

$\mathrm{Na}$ América Latina, muitos estudantes procuram a formação jurídica como um meio para reforçar uma profissão preexistente, como é o caso de muitos funcionários públicos de nível médio.

As principais atividades e funções desempenhadas pelos graduados em direito são: magistratura, em nível federal, estadual e municipal, em alguns Estados; Ministério Público, como Procuradores da República e Promotores de Justiça; auxiliares da administração judicial, como escrivãos, oficiais de justiça; administradores do Estado, como Procuradores do Estado, defensores públicos, assessores jurídicos legislativos e funcionários cartorários; funcionários da segurança pública, como dos órgãos policiais e penitenciários; docentes em instituições públicas e privadas; e advogados litigantes, empregados, consultores, investigadores, assessores jurídicos de empresas e de organizações não-governamentais.

\subsection{Sistema de créditos}

O Projeto Tuning também averiguou como é o sistema de créditos acadêmicos na América Latina.

Como crédito, entende-se a unidade de medida do trabalho acadêmico, que requer do estudante competências profissionais de nível superior. Ele pode basear-se em distintos parâmetros como a carga horária, estudos independentes, estudos de campo, trabalhos em laboratórios, oficinas e outros, bem como em resultados de aprendizagem $^{11}$.

11 REFLEXIONES y Perspectivas de la Educación Superior en América Latina: Informe Final - Proyecto Tuning América Latina (2004-2007), p. 415. 
Um sistema nacional de créditos acadêmicos existe apenas em El Salvador e Honduras em um universo de 16 países consultados. Outros seis países prevêem alguns convênios, têm un sistema para determinadas atividades ou realizam estudos com essa finalidade ${ }^{12}$.

Em algumas ocasiões, os currículos das diferentes instituições não estão integrados sequer no interior de um mesmo país.

\subsection{Resultados das pesquisas realizadas sobre as competências específicas da disciplina}

Grupo de Trabalho elaborou uma lista com 24 competências específicas para o direito. A consulta referiu-se ao nível de importância atribuído a cada uma delas e ao grau de realização das mesmas. Por exemplo, a lista começava com "conhecer, interpretar e aplicar os princípios gerais do direito e do ordenamento jurídico" e terminava com "agir de maneira leal, diligente e transparente na defesa do interesse das pessoas representadas".

O questionário sobre as competências específicas foi aplicado em 13 países, tendo sido respondido por mais de dois mil acadêmicos, empregadores, estudantes e graduados entre abril e maio de 2006.

Posteriormente, em Bruxelas, em junho de 2006, os resultados foram analisados, quando então foram detectados os graus de realização e de importância atribuído às competências.

As quatro competências mais importantes para os quatro grupos de entrevistados foram: capacidade de racionalizar e argumentar juridicamente; agir de maneira leal, diligente e transparente na defesa de interesses das pessoas que representa; conhecer, interpretar e aplicar os princípios gerais do direito e do ordenamento jurídico; ser consciente da dimensão ética da profissão jurídica e da responsabilidade social do graduado em direito e agir em correspondência.

As quatro menos importantes para os quatro grupos de entrevistados foram: conhecer uma língua estrangeira que permita o desempenho eficiente no âmbito jurídico; capacidade de trabalhar em equipes interdisciplinares como peritos em direito, contribuindo de maneira efetiva às suas tarefas; capacidade de exercer a sua profissão trabalhando em equipe com colegas; e considerar a pertinência do uso de meios alternativos na solução de conflitos.

As duas competências mais relevantes para os acadêmicos e para os estudantes foram capacidade de racionalizar e argumentar juridicamente e atuar de maneira leal, diligente e transparente na defesa dos interesses das pessoas que representa.

As duas competências mais relevantes para os graduados foram exatamente o inverso das vistas acima.

\footnotetext{
${ }^{12}$ REFLEXIONES y Perspectivas de la Educación Superior en América Latina: Informe Final - Proyecto Tuning América Latina (2004-2007), p. 415-416
} 
$\mathrm{E}$ as duas competências mais relevantes para os empregadores foram atuar de maneira leal, diligente e transparente na defesa dos interesses das pessoas que representa e conhecer, interpretar e aplicar os princípios gerais do direito e do ordenamento jurídico.

Os dirigentes do projeto expuseram que, em todos os grupos consultados, nenhuma das competências específicas recebeu uma nota menor que 3 , em uma escala de 1 a 4 , o que demonstra que não há competência considerada sem importância. Os resultados revelam pouca distância numérica entre a competência mais importante e a menos importante. Também, que a priorização das competências capacidade de racionalizar e argumentar juridicamente e atuar de maneira leal, diligente e transparente na defesa dos interesses das pessoas que representa pode ser interpretada como um sinal de alerta com respeito à concepção tradicional do ensino do direito. Nesse sentido, a primeira das competências revela uma forte valorização do papel do advogado como profissional que facilita a solução de problemas jurídicos e a segunda das competências revela a apreciação do comportamento ético dos advogados, dos quais se espera que dêem confiança a seus clientes e à sociedade em geral.

A $5^{\text {a }}$. e última Reunião Geral do Projeto ocorreu em fevereiro de 2007, na Cidade do México.

Outras informações encontradas pelo Projeto Tuning América Latina ${ }^{13}$ conduzem à conclusão de que é patente a crise do modelo de formação jurídica, caracterizado por uma excessiva valorização da memorização e da análise básica de normas jurídicas.

A realidade apontada é que, comprovadamente, um grande número de alunos ingressa em instituições de ensino superior sem ter adquirido as competências básicas de leitura e escrita de textos, capacidades para o raciocínio lógico matemático, capacidade de análise e de síntese, capacidade de argumentação, etc.

Os resultados do Projeto Tuning América Latina, produtos de uma pesquisa em distintos grupos sociais em cada um dos países, foram apontados como de grande relevância especialmente por terem permitido a elaboração de uma caracterização da educação superior no Continente e constatado a necessidade de modificações no ensino do direito.

Tuning América Latina representou uma positiva e intensa experiência de diálogo. Nesses anos iniciais do Projeto, foi construído um espaço de diálogo que contribuirá para a criação de um sistema educativo mais sensível aos novos desafios, no qual foram discutidos com profundidade, por áreas temáticas, aspectos como a definição de perfis através de competências.

São previstos para os próximos anos a discussão e o debate do projeto e dos seus resultados no interior das universidades e dos países participantes, bem como constitui um desafio básico a criação, nas faculdades de direito, de um espaço de reflexão crítica dos atores comprometidos com o ensino, que devem avançar através da busca de consensos. Quanto ao objetivo da mobilidade de estudantes e professores, há a proposta do incremento dos estudos para o avanço da comparabilidade das titulações.

\footnotetext{
${ }^{13}$ REFLEXIONES y Perspectivas de la Educación Superior en América Latina: Informe Final - Proyecto Tuning América Latina (2004-2007). 432p
} 
A realização do Projeto Tuning América Latina, em resposta ao meu primeiro questionamento, vem explicitar que há, sim, estudos na América Latina a exemplo das iniciativas propostas em Bolonha, em especial quanto à adoção de um sistema de educação superior baseado em competências. As iniciativas têm abrangido o ensino jurídico.

Todavia, a América Latina não tem uma data para criar um Espaço de Educação Superior, tampouco conta com um marco político tão encaminhado como o que possui a Europa $^{14}$. As principais diferenças entre o Tuning Europa e o Tuning América Latina se radicam no momento político que vive a Europa e aquele da América Latina. A Europa possui um projeto comum. A União Européia está cada vez mais ampla, diversa e multicultural e vem avançando em seu processo de integração ${ }^{15}$. Já a América Latina avança em diferentes processos de integração regional ou sub-regional, em ritmos diversos.

A minha segunda questão é saber se estas propostas servem para o ensino jurídico. O que o Projeto Tuning propõe ainda não está implementado para nenhuma ciência. As dúvidas de se as suas estratégias são válidas para o direito aumentam na medida em que são expostas as realidades dos países latino-americanos e dos blocos de integração que poderiam se responsabilizar por tais questões sociais.

\section{Referências ao ensino jurídico em países latino-americanos}

O que existe em matéria de harmonização de sistemas educativos foi construído pelo Convênio Andrés Bello, que reúne diversos países latino-americanos, com sede em Bogotá. Este convênio, assinado em 1970, criou uma organização internacional de caráter intergovernamental que tem como objetivo o fortalecimento dos processos de integração educativa e a configuração e o desenvolvimento de um espaço cultural comum ${ }^{16}$. Por ter estabelecido um regime de equivalência de títulos, é apontado como um processo pioneiro na América Latina. A Espanha aderiu ao convênio em 1990 e isso permite a muitos estudantes $\mathrm{o}$ ingresso em universidades espanholas.

$\mathrm{Na}$ América Central, há um antecedente pouco conhecido que é o Tratado de Confratemidad Centroamericana de 1934, que se refere à unificação da educação elementar, secundária e profissional e superior. Em 1948, foi criada a Confederación de Universidades Centroamericanas, origem do Consejo Superior Universitario. Em 1949, foi criada a Unión de Universidades Latinoamericanas, com sede em Guatemala.

A Comunidade Andina tem um programa para implementar um esquema de harmonização curricular em nível da subregião entre Colômbia, Equador, Peru e Bolívia.

No sistema interamericano da Organização dos Estados Americanos, as Jornadas de Direito Internacional têm sido um foro para a discussão de temas ligados ao ensino em uma

\footnotetext{
${ }^{14}$ GONZÁLES, Julia; WAGENAAR, Robert; BENEITONE, Pablo. Tuning-América Latina: un Proyecto de las Universidades. Revista Iberoamericana de Educación, n. 35, a. 2004, p. 161

15 GONZÁLES, Julia; WAGENAAR, Robert; BENEITONE, Pablo. Tuning-América Latina: un Proyecto de las Universidades. Revista Iberoamericana de Educación, n. 35, a. 2004, p. 160.

${ }^{16}$ MOROSINI, Marilia Costa (editora). Enciclopédia de Pedagogia Universitária: glossário. Brasília: Instituto Nacional de Estudos e Pesquisas Educacionais Anísio Teixeira, 2006.v. 2. p. 139-140
} 
matéria específica, o direito internacional, tanto público como privado. Ainda que não seja mencionada a harmonização dos currículos, há uma preocupação em relação à importância do ensino do direito internacional, assim como a sua integração obrigatória nos programas de estudos.

Vejam-se algumas realidades em particular:

República Dominicana: há catorze instituições onde se pode estudar direito, o que é considerado muito, pois se trata de um país pequeno. Talvez por isso o país apresente a maior taxa de advogados por cada 100 mil habitantes do continente, que é 46,24 , perante uma média de $12,38^{17}$. Uma das instituições é pública. $O$ sistema jurídico se baseia na Família Romano-Germânica. O direito civil e comercial está baseado no sistema francês e até um pouco mais de um ano o código processual penal era uma cópia do francês. Agora entrou um novo em vigor, que contempla aspectos do sistema francês, do anglo-saxão e do norte-americano. $O$ curso de direito tem uma duração de quatro anos. O currículo tem aproximadamente 30 ou 35 matérias e depende da universidade e da filosofia da mesma. Muito comum de constar nele é um expressivo número de disciplinas de francês. Ao finalizarem os estudos os estudantes devem apresentar uma monografia para graduarem-se e devem prestar juramento na Suprema Corte de Justiça para obter a habilitação profissional.

Costa Rica: a formação dos juristas é positivista, com uma base jus-filosófica fundamentada na teoria, muito contraria aos sistemas baseados em formação prática e estudos de casos. Há 39 cursos no país, o que é considerado muito, pois se trata de um país pequeno. As faculdades públicas operam por semestres e as privadas por quadrimestres. Geralmente o curso tem uma duração de 5 anos.

Chile: não há antecedentes de harmonização de currículos nas faculdades de direito chilenas.

Equador: o país possui um acordo específico de reconhecimento mútuo de diplomas de direito e outras carreiras com o Chile, o que permite àquelas pessoas que obtiverem um diploma no Equador ou no Chile exercerem diretamente a profissão de advogado sem a necessidade de reconhecimento ou homologação alguma.

Venezuela: não há esforços específicos de harmonização dos programas de estudo de direito, ainda que se pareçam bastante os programas das 22 fạculdades venezuelanas.

Argentina: o ensino jurídico é oferecido por 17 faculdades de direito públicas e outras tantas privadas. O currículo é integrado por, normalmente, 26 a 35 disciplinas obrigatórias.

Uruguai: há apenas uma faculdade de direito pública, que é a Universidad de la República.

\footnotetext{
17 PEÑA GONZÁLEZ, Carlos. Características y Desafios de la Enseñanza Legal Latinoamericana. 7 p. Disponivel em: http: /www.aals.org/2000intemational/. Acesso em 15.11.2007.
} 
Há certa unanimidade entre os juristas latino-americanos em afirmar que essas realidades são diversas e constituídas por culturas distintas, o que impede pensamentos de uma harmonização de sistemas educativos, por exemplo, entre Caribe e Brasil, ou mesmo entre Peru, Equador e Brasil.

O problema principal que explicaria a falta de intenções de unificação é o pouco interesse recíproco que tradicionalmente tem entre si os países da região. Eles preferiram olhar a Europa antes de ver a realidade de seus vizinhos. Há uma espécie de complexo de inferioridade frente à Europa e aos Estados Unidos da América e, por isso, se considera que as experiências dos países vizinhos são de pouca qualidade.

A integração latino-americana é carente e isso fez com que a questão jurídica não seja muito valorizada. Se parte da idéia de que o Direito é um produto estritamente nacional que responde às necessidades nacionais exclusivamente e por isso nada há para se uniformizar com os países vizinhos. O que se busca é que os títulos que sejam outorgados nos países sejam reconhecidos na Europa, principalmente na Espanha. Em suma, os países não parecem ter descoberto razões para uniformizar os programas de ensino em direito.

\section{Ensino Jurídico no Mercosul}

Eu gostaria de dar atenção agora a realidades próximas. Por isso vou tratar do Mercosul em separado.

\subsection{Disposições do processo de integração}

O Mercosul é um bloco de integração econômica criado pelo Tratado de Assunção em 1991, que reúne quatros Estados, a saber Brasil, Argentina, Paraguai e Uruguai. Ele encontra-se em uma etapa nebulosa entre uma zona de livre comércio não-concluída e uma união aduaneira imperfeita, portanto longe do alcance de um mercado comum. A possível adesão da Venezuela é debatida.

O processo de integração do Mercosul tem planos estratégicos para a área da educação. O Mercosul Educativo, por exemplo, nascido em 1992, objetiva a integração educativa regional, o conhecimento dos sistemas de educação superior e a elaboração de políticas para a harmonização dos mesmos ${ }^{18}$.

O último plano foi fixado para o período de 2006 a 2010. Ele inclui, entre outros objetivos, a mobilidade acadêmica e profissional e a cooperação interinstitucional. Atualmente, o Mercosul implementa um Mecanismo Experimental de Créditos de cursos de graduação.

Estas discussões pouco avançam em virtude das diferenças regionais. O sistema argentino de formação do profissional do direito aproxima-se mais do sistema europeu, enquanto o brasileiro do modelo norte-americano, por exemplo.

18 MOROSINI, Marilia Costa (editora). Enciclopédia de Pedagogia Universitária: glossário. Brasília: Instituto Nacional de Estudos e Pesquisas Educacionais Anísio Teixetra, 2006. v. 2. p. 149-151. 
Nos últimos anos, tem sido valorizada a multilateralidade funcional, especialmente através da geração de instrumentos flexíveis de cooperação, como redes universitárias e alianças estratégicas. Esse é o caso, por exemplo, da Associação de Universidades do Grupo Montevidéu ${ }^{19}$, da qual a Universidade Federal do Rio Grande do Sul, onde eu exerço as minhas atividades, participa.

O tema mais freqüente no Mercosul é o do reconhecimento dos títulos universitários pelos demais Estados-partes do processo de integração econômica. O reconhecimento é unicamente para o exercício de atividades acadêmicas de docência e pesquisa, não produzindo efeitos para o exercício da profissão. Os postulantes deverão submeter-se às mesmas exigências previstas para os nacionais do Estadoparte onde pretendem exercer atividades acadêmicas. Nesse sentido é o recente Parecer CNE/CES n. 106/2007, de 9 de maio de 2007, do Conselho Nacional de Educação do Brasil, sobre a admissão de títulos de pós-graduação obtidos nos Estados-partes do Mercosul. O Brasil é muito requisitado a promover reconhecimentos, mormente por nacionais que realizaram cursos nos países vizinhos.

O Mercosul, em 14 de junho de 1999, assinou o Acordo de Admissão de Títulos e Graus Universitários para o Exercício de Atividades Acadêmicas nos seus Estadospartes, instalando um procedimento de admissão que parecia diferenciar-se do reconhecimento.

Uma legislação brasileira de 23 de agosto de 2005 internalizou o Acordo de Admissão. O Conselho Nacional de Educação foi instado a manifestar-se oficialmente sobre como as universidades deveriam proceder em relação a esses títulos.

A discussão girou em torno dos seguintes aspectos: que o Acordo, em seu artigo primeiro, prevê que a referida admissão deveria ocorrer segundo procedimentos e critérios a serem estabelecidos para a implementação do Acordo, o que ainda não existe; que os órgãos governamentais deveriam criar uma padronização, para evitar que o interessado deva provar suas credenciais em mais de uma instituição quando ele trabalha em mais de uma instituição; que a aplicabilidade dada ao título seria exclusiva para a instituição de ensino brasileira que proceder ao exame do mesmo para os fins de docência e pesquisa; e que o Acordo de Admissão de títulos do Mercosul não afasta a aplicabilidade do mecanismo, brasileiro de revalidação e reconhecimento de títulos de que trata a Lei de Diretrizes e Bases da Educação n. 9.394, de 1996, em seu artigo 48, que produz efeitos distintos do efeito produzido pelo novo procedimento.

Em síntese, as discussões sobre o Acordo de Admissão convergiram para o seguinte entendimento: que os organismos competentes para proceder a admissão dos títulos no Brasil seguem sendo as universidades; que essas ainda não contam com o acesso às informações

\footnotetext{
${ }^{19}$ MOROSINI, Marilia Costa (editora). Enciclopédia de Pedagogia Universitária: glossário. Brasília: Instituto Nacional de Estudos e Pesquisas Educacionais Anisio Teixeira, 2006. v. 2. p. 149 e PINTO, Mónica. Legal Education in Argentina and other South Latin American Countries. 10 p. Disponível em: http://wrwaals.otg/2000international/. Acesso em 15.11.2007.
} 
sobre as agências credenciadas, os critérios de avaliação e os cursos credenciados, que deveriam estar disponíveis através do Sistema de Informação e Comunicação do Mercosul, segundo o Acordo de Admissão; que o Acordo de Admissão não instituiu a validade automática no Brasil dos títulos obtidos nos demais Estados-partes do Mercosul; que para as atividades profissionais é necessário o reconhecimento e que a atividade de ensino é uma atividade profissional; que o instituto da admissão, previsto no Acordo, é para as ações de caráter temporário, como parcerias multinacionais, grupos de pesquisa, co-orientação de pósgraduandos, ministrar aulas como professor colaborador, organizar obras em conjunto, pois uma demora do reconhecimento inviabilizaria o intercâmbio de docentes, que é o objetivo do Acordo. Nesse sentido, não se justificaria o ônus do reconhecimento a quem não pretende permanecer no Brasil; e que um entendimento contrário a esse dispensaria, por exemplo, um professor de direito, responsável pela qualidade das aulas dos futuros advogados, das exigências feitas a um advogado que queira exercer a profissão.

O parecer diz que o Acordo de Admissão de títulos do Mercosul não afasta a aplicabilidade do mecanismo brasileiro de revalidação e reconhecimento de títulos de que trata a Lei de Diretrizes e Bases da Educação n. 9.394, de 1996, em seu artigo 48, que produz efeitos distintos do efeito produzido pelo novo procedimento, e que o instituto da admissão, previsto no Acordo, é para as ações de caráter temporário, como parcerias multinacionais, grupos de pesquisa, co-orientação de pós-graduandos, ministrar aulas como professor colaborador e organizar obras em conjunto.

A doutrina tem se manifestado contra essa solução, ao entender que esses títulos seriam válidos por si, sem a necessidade de qualquer reconhecimento, respeitadas as atividades de docência e pesquisa, uma vez que o Acordo teria sido integrado à ordem jurídica interna na mesma hierarquia da Lei de Diretrizes e Bases da Educação ${ }^{20}$.

A conclusão é que as regras do Mercosul são ainda insuficientes para a atuação de advogados e docentes nos Estados-partes. Ainda que todos os países reconheçam constitucionalmente a igualdade entre nacionais e estrangeiros para fins de exercício de profissões e atividades econômicas.

O Mercosul não estabelece nenhuma regra específica sobre o exercício da advocacia em seus tratados. Há apenas uma referência genérica sobre 'livre circulação de bens, serviços e fatores produtivos entre os países" ${ }^{\prime 21}$. Em verdade, a educação não é um item expressamente mencionado no Tratado de Assunção ${ }^{22}$.

\footnotetext{
20 NUNES, Alceu Ferreira. A validade dos diplomas obtidos nos países do Mercosul. Jus Navegandi, Teresina, ano 11, n. 1462, 3 jul. 2007. Disponível em www.jusnavegandi.com.br. Acesso em 3 de novembro de 2007

21 JAEGER JUNIOR, Augusto. Mercosul e a livre circulação de pessoas. São Paulo: LTr, 2000.190 p.

22 PINTO, Mónica. Legal Education in Argentina and other South Latin American Countries. 10 p.
} 


\subsection{Legislações dos Estados-partes do Mercosul}

Nessa pesquisa, não foram encontrados estudos comparativos sobre como ocorre o ensino jurídico nos países do Mercosul ${ }^{23}$. Todavia, foi encontrada uma tese comparativa sobre o exercício profissional do advogado nos países do Mercosul, da lavra de Eliseu Mânica $^{24}$. Seu estudo aponta as semelhanças e diferenças existentes nos critérios e procedimentos de habilitação do advogado nos quatro países.

Constatações que muito interessam tratam da heterogeneidade dos currículos dos cursos de direito e das dificuldades para o reconhecimento dos diplomas, ademais dos obstáculos gerados pelas diferenças nos critérios adotados para a habilitação profissional.

Ante a não-existência, hoje, de uma harmonização em nenhuma dessas questões, o autor elabora sugestões para promover a convergência nos currículos, como pressuposto para o reconhecimento dos diplomas, e para estabelecer critérios comuns para a habilitação profissional.

De fato, diferentemente do Mercosul, as legislações internas dos Estados-partes definem critérios e normas procedimentais para a habilitação profissional, alguns semelhantes e outros diferentes.

Tome-se por exemplo a Argentina. Nesse Estado-parte, os critérios de habilitação do advogado são estabelecidos por leis provinciais e das cidades. $\mathrm{O}$ ato de inscrição é realizado perante o Colégio Público de Advogados. Os critérios para o graduado em direito obter inscrição nele são os seguintes: acreditar a identidade pessoal mediante a exibição de documento; apresentar título de advogado expedido ou reconhecido por autoridade nacional; informar o domicílio real e constituir um especial na Capital Federal; declarar, sob juramento, não estar abrangido por nenhuma das incompatibilidades ou impedimentos da lei; prestar juramento profissional; e pagar as taxas estabelecidas.

Semelhante ao que acontece na Argentina, no Brasil o advogado se habilita perante a Ordem dos Advogados do Brasil. O estudante de advocacia pode inscreverse nesse órgão, como estagiário, a partir do quarto ano do curso.

Todavia, algumas diferenças são expressivas: por exemplo, somente o Brasil estabelece uma prova para o bacharel em direito poder se inscrever como advogado.

De fato, a partir da vigência da nova legislação sobre o exercício da profissão de advogado, em 1994, o Exame da Ordem passou a ser obrigatório no Brasil. Trata-se de um

23 Sobre o ensino jurídico no Brasil, ver as obras BASTOS, Aurélio Wander. O ensino jurídico no Brasil. Rio de Janeiro: Lúrnen Júris, 1998. 371 p; RODRIGUES, Horácio Wanderlei. Pensando o ensino do direito no século XXI: diretrizes curriculares, projeto pedagógico e outras questões pertinentes. Florianópolis: Fundação Boiteux, 2005. 360 p; , e RODRIGUES, Horácio Wanderlei; JUNQUEIRA, Eliane Botelho. Ensino do direito no Brasil: diretrizes curriculares e avaliação das condições de ensino. Florianópolis: Boiteux, 2002.560 p. Sobre o ensino jurídico na Atgentina, ver PINTO, Mónica. Legal Education in Argentina and other South Latin American Countries. $10 \mathrm{p}$

24 MÂNICA, Eliseu. Os Critérios de Habilitação do Advogado nos Estados Partes do Mercosul. Florianópolis: Curso de Pósgraduação em Direito (UFSC). Dissertação de Mestrado, 2002.157 p. Ver também JAEGER JUNIOR, Augusto. O exercício da advocacia no Mercosul. Revista Vip, a. 4, n. 15. Santo Ângelo: Jomal a Tribuna Regional, jul. 2000.p. 9-10 e VIEIRA, Debora Cristina $O$ exercício da advocacia no Mercosul frente à livre circulação de serviços e trabalhadores. In: RODRIGUES, Horácio Wanderlei (Org.). Solução de Controvérsias no MERCOSUL. Porto Alegre: Livraria do Advogado, 1997. p. 113-132 
exame não realizado na instância universitária, nem por autoridades educacionais, algo até então impensado e percebido como um atentado contra a autonomia das universidades pela literatura latino-americana ${ }^{25}$. Segundo a tradição latino-americana o controle para o exercício profissional depende das universidades ou de um órgão judicial. Ele é realizado três vezes por ano. Ele é integrado por duas provas. A primeira é objetiva, contendo questões de múltipla escolha. A segunda prova abrange a redação de peça profissional em uma das áreas do direito e a resposta de até cinco questões práticas envolvendo problemas jurídicos. No Brasil há 600 mil advogados inscritos dentre os 2 milhões de bacharéis. A exigibilidade do exame e o fato de ele reprovar 65 por cento dos candidatos geram muitos protestos e projetos legislativos exigindo o fim do mesmo.

No Paraguai e no Uruguai a habilitação é formalizada junto ao órgão máximo do Poder Judiciário.

Por fim, é curioso notar que no Uruguai os títulos universitários de advogado recebem a denominação oficial de doutor em direito. Essa definição terminológica pode gerar certa confusão, pois esse e os demais Estados-partes do Mercosul possuem o título de doutor em direito obtido por quem realiza o curso de doutorado.

E que o estrangeiro, no Paraguai, pode enfrentar dificuldades para advogar, já que o país tem duas línguas oficiais, o castelhano e a língua indígena guarani, bem como pelo fato de a constituição prever que, nos conflitos jurisdicionais, será levado em conta o direito consuetudinário dos índios.

Em conclusão de seu estudo comparativo, Eliseu Mânica propõe medidas para viabilizar a advocacia no Mercosul, obstaculizada pelas diferenças substanciais nos critérios e procedimentos para a habilitação profissional e na heterogeneidade dos currículos dos cursos de direito. Prima o autor por uma necessidade de convergência dos mesmos.

\subsection{Iniciativas para um currículo mínimo para o ensino do direito}

O Paraguai não possui regras nacionais definindo diretrizes curriculares aos cursos. Cada universidade tem competência para elaborar e pôr em prática os seus planos de ensino. Os currículos dos cursos jurídicos no Uruguai, a exemplo do Paraguai, não possuem regras nacionais uniformes. Argentina e Brasil possuem diretrizes curriculares básicas nacionalmente unificadas. Mesmo assim, não são normas rígidas. Veja-se a situação.

$\mathrm{Na}$ Argentina, leis federais fixam normas gerais de maneira flexível, deixando aos projetos pedagógicos dos cursos de direito a normatização de aspectos específicos do currículo, atendendo a necessidades da região em que se situa o curso e o mercado de trabalho. Os cursos têm carga horária mínima de duas mil e seiscentas horas e duração mínima de quatro anos. Dentro desses parâmetros, os cursos definem seus projetos pedagógicos. A diversidade dos currículos parece ser uma característica.

25 Ver PÉREZ PERDOMO, Rogelio. La Profesión de Abogado y la Educación Jurídica. Revista del Colegio de Abogados del Distrito Federal. Venezuela: n. 150, tercera etapa, 1992. p. 135-152. 
No Brasil, a questão está em duas legislações de 1994 e 1996 que, respectivamente, fixam as diretrizes curriculares ${ }^{26}$, o conteúdo mínimo dos cursos e as diretrizes e bases da educação nacional. Os cursos de direito devem ter três mil e setecentas horas e serem integralizados em no mínimo cinco e no máximo oito anos. Há certa harmonização interna em virtude da obrigatoriedade dessas regras.

De 1827 a 1962, os cursos jurídicos no Brasil tiveram um currículo único, imposto pelo governo, nacional, rígido e invariável, constituído de nove disciplinas, a ser cumprido em cinco anos, refletindo os aspectos políticos e ideológicos do Império, com forte influência do Direito Natural e do Direito Público Eclesiástico. Durante esse período, até a Proclamação da República, só houve uma alteração curricular, em 1854, que gerou a inclusão das disciplinas de Direito Romano e Direito Administrativo. Em 1962 é que uma mudança de maior profundidade introduziu o conceito de currículo mínimo nos $\operatorname{cursos}^{27}$. Essa idéia ensejava que as instituições implantassem seus currículos plenos, adaptando os cursos de todo o país às suas realidades e necessidades regionais ou mesmo à ideologia que os sustentava ${ }^{28}$.

A década de 90 foi pródiga em críticas a esse modelo curricular. Os movimentos por mudanças foram muito apoiados pela Ordem dos Advogados do Brasil. Finalmente, em 1994, uma nova legislação emanada do Ministério da Educação melhor considerou a realidade mercadológica. As diretrizes curriculares, até então bastante rígidas, tornaram-se flexíveis. Entre outras alterações, as disciplinas de direito romano, direito internacional e filosofia do direito tornaram-se obrigatórias e novas disciplinas como direito do consumidor e direito ambiental foram incorporadas aos currículos como eletivas. Interesses emergentes geraram uma diversificação da oferta curricular. Além disso, para concluir o seu curso, o estudante deve preparar um trabalho escrito, cuja elaboração é desenvolvida sob a orientação de um professor, devendo ser defendido oralmente perante uma comissão formada, em geral, por três professores de direito. A aprovação desse trabalho é requisito obrigatório para a colação de grau.

Em 2002, uma tentativa govemamental de permitir que os cursos de direito pudessem ser concluídos em três anos, a critério de cada instituição, recebeu forte crítica nacional ${ }^{29}$. Entidades de representação, como a Ordem dos Advogados do Brasil ${ }^{30}$ e a Associação Brasileira de Ensino do Direito - ABEDi, entenderam que cinco anos representam o tempo ideal para a formação jurídica e a conseqüente construção do conhecimento técnico-científico necessário para um ingresso no mercado de trabalho.

\footnotetext{
26 Ver a questão em RODRIGUES, Horácio Wanderlei. Pensando o ensino do direito no século XXI: diretrizes curriculares, projeto pedagógico e outras questões pertinentes. Florianópolis: Fundação Boiteux, 2005. $360 \mathrm{p}$

27 Ver o tema em RODRIGUES, Horácio Wanderlei. Pensando o ensino do direito no século XXI: diretrizes curriculares, projeto pedagógico e outras questões pertinentes. Florianópolis: Fundação Boiteux, 2005.360 p

28 CARLINI, Angélica Lucia. Currículo em Direito: mudanças e percepções. $19 \mathrm{p}$

29 RODRIGUES, Horácio Wandetlei. A ABEDi e as novas diretrizes curriculares para os Cursos de Direito. Anuário da ABEDi, Florianópolis, Fundação Boiteux, v. 3, n. 3, p. 53-81, 2005.

${ }^{30}$ O papel da Ordem dos Advogados do Brasil nas profundas mudanças que ocorreram na última década na formação do bacharel em direito no Brasil e nos processos de criação $€$ aprovação de cursos instalados pode ser conferido em FELIX, Loussia P. Musse. Novas Dimensões da Atuação Jurídica: o Papel de Advogados, Burocratas e Acadêmicos na Redefiniçăo da Formação e das Funções dos Operadores Jurídicos. $26 \mathrm{p}$
} 
Hoje as diretrizes curriculares fornecem linhas gerais para os cursos elaborarem seus projetos pedagógicos com autonomia e criatividade, de acordo com as suas vocações, demandas sociais e mercado de trabalho.

As diretrizes estão estruturadas em três eixos de formação: fundamental, profissional e prática A formação fundamental, por exemplo, contempla as disciplinas de Antropologia, Ciência Política, Economia, Ética, Filosofia, História, Psicologia e Sociologia. Elas estabelecem, quanto ao perfil desejado do graduando, uma sólida formação geral, humanística e axiológica, capacidade de análise, domínio de conceitos e da terminologia jurídica, adequada argumentação, interpretação e valorização dos fenômenos jurídicos e sociais ${ }^{31}$. Tudo isso, segundo o artigo $3^{\circ}$. da Resolução $\mathrm{CNE} / \mathrm{CES}$ n. 9/2004, deve vir aliado a uma postura reflexiva e de visão crítica que fomente a capacidade e a aptidão para a aprendizagem autônoma e dinâmica, indispensável ao exercício da ciência do direito, da prestação da justiça e do desenvolvimento da cidadani $a^{32}$. Alguns cursos de direito flexibilizam até quarenta por cento da estrutura curricular e outros possuem espaço para serem cursadas catorze disciplinas eletivas em dez semestres.

Essa flexibilidade promoveu uma ruptura com a concepção de que os cursos são compostos de uma extensa e variada relação de disciplinas e conteúdos justapostos e que não passam de uma repetição do já pensado, de uma mentalidade conteudista, de prioridade ao domínio formal de conteúdos, em detrimento de atitudes, condutas e habilidades. $E$ onde o espaço para o exercício da autonomia era diminuto.

Mais detidamente, Angélica Lucia Carlini, em estudo em que analisa como os currículos foram concebidos e implantados no Brasil ao longo de sua trajetória histórica, observa que nos últimos anos houve até uma sofisticação na denominação de algumas disciplinas introduzidas nos currículos e uma quase que surda competição entre as escolas de direito para ver qual delas construía o currículo mais diferenciado ${ }^{33}$. Esse caráter de maior liberdade para a organização dos currículos resta evidenciado pela legislação, que permite que, respeitado o currículo mínimo, o curso construa uma ou mais áreas de especialização de acordo com as vocações e demandas sociais e de mercado de trabalho.

Carlini aponta, todavia, que as escolas de direito não têm aproveitado essa liberdade de que desfrutam na construção de seus currículos, adotando-se, na maior parte dos casos, o currículo mínimo como o currículo pleno ${ }^{34}$. As mudanças não apontam para uma efetiva transformação da visão tradicional. Os currículos dos cursos seguem sendo organizados da mesma forma que as estantes das livrarias. A realidade mostra, também, que quem muito inovou, com "propostas transgressoras" 35 , o mercado assassinou.

\footnotetext{
$31 \mathrm{Na}$ doutrina alemã, o papel das Grundlagenfächer als Orientierungshilfe pode ser conhecido em BALDUS, Christian. Grenzbestimmung und Methodenfindung: Grundlagenfächer in der Juristenausbildung und Aufgaben der juristischen Dogmengeschichte. Studentische Zeitschrift für Rechtswissenschaft Heidelberg, StudZR, Ausgabe 2/2005. 22 p.

32 MOTA, Ronaldo. Como fazer direito? Jomal O Estado de Minas Gerais, edição do dia 11 de outubro de 2007.

33 CARLINI, Angélica Lucia. Currículo em Direito: mudanças e percepções. $19 \mathrm{p}$

34 CARLINI, Angélica Lucia. Currículo em Direito: mudanças e percepções. $19 \mathrm{p}$.

35 FELIX, Loussia P. Musse. Novas Dimensões da Atuação Jurídica: o Papel de Advogados, Burocratas e Acadêmicos na Redefinição da Formação e das Funções dos Operadores Jurídicos. 26 p.
} 
As disciplinas dogmáticas são a exposição extensiva das grandes leis. A duração de cada uma não é determinada por critérios de relevância e de pertinência ao entorno social em que vive o estudante, mas pelo tamanho de cada uma dessas grandes leis ${ }^{36}$.

Um curso formado nesses parâmetros induz a formação de um bacharel que possui conhecimento extensivo, memorizado e abrangente de todas as áreas do direito positivo, que reproduz automaticamente a perspectiva fornecida pelos manuais, pelas cópias xérox de proporções mínimas que lhe foram disponibilizadas facilmente em locais pré-determinados e pelas palestras que pôde assistir ${ }^{37}$.

O estudo dos currículos dos países do Mercosul mostrou a Eliseu Mânica, todavia, que não é nessa questão que reside um elevado número de divergências. Mas elas se apresentam, sim, nos parâmetros mínimos de duração dos cursos, de carga horária, freqüência exigida dos alunos, na exigência de monografias finais e de provas que habilitam à profissão. Diferentemente do Brasil, no Paraguai os alunos podem solicitar ao Conselho Diretivo da universidade a exoneração da obrigação de assistir às aulas por razões de residirem há mais de quarenta quilômetros da Capital.

Estas divergências são substanciais e inviabilizam o reconhecimento dos títulos de graduação em direito no Mercosul. Isso, por sua vez, impede o desenvolvimento da mobilidade e de uma advocacia comum no bloco. No estágio atual do Mercosul, as regras existentes são insuficientes para a atuação do advogado nacional de um Estado-parte em qualquer outro.

Fora do ambiente acadêmico, um currículo mínimo para o ensino do direito já foi objeto de preocupação do Conselho de Colégios e Ordens de Advogados do Mercosul - COADEM, órgão que congrega entidades de classe de nove países latino-americanos, por ocasião de uma reunião ocorrida em 5 de maio de 2004, em Rosário, na Argentina. Essa entidade, antes, havia lançado um Protocolo de Regulamentação da Atuação Profissional Transfronteiriça dos Advogados nos Páses do Mercosul, que permite o desempenho de atividades de consultoria e assessoria jurídica sem a obrigatoriedade do reconhecimento dos títulos ${ }^{38}$. Ele foi aprovado pela Ordem dos Advogados do Brasil em 16 de agosto de 2004. A sua implementação, todavia, depende de processos de transposição das normas nos sistemas legais dos países e de cláusulas de reciprocidade.

Conhecidos esses dados referentes à heterogeneidade dos currículos dos cursos de direito entre os países latino-americanos e mesmo dentro deles e as demais diferenças apontadas, eu poderia responder a questão de se as tentativas de harmonização de sistemas educativos servem ao direito com um não.

36 VANZELLA, Rafael Domingos Faiardo (org). Experiências e Materiais sobre os Métodos de Ensino-Aprendizado da Direito GV. São Paulo: Fundação Getúlio Vargas, 2007. p. 7-23.

37 OLIVEIRA JÚNIOR, José Alcebíades de. Repensando o ensino do Direito para sociedades multiculturais - da Pedagogia ao currículo. Revista da Faculdade de Direito da Universidade Federal do Rio Grande do Sul. Porto Alegre: Sulina, v. 25, dez./ 05 , p. 109-120.

38 Ver Ata da Assembléia do COADEM do dia 5 de maio de 2004. Disponível em www.coadem.org. Acesso em 12 de novembro de 2007. 
Para responder a última questão a que me propus, sobre porque não houve ou porque essas experiências não tiveram sucesso, eu vou explicar melhor a realidade do Brasil, em função do seu papel no ensino jurídico na América Latina.

\section{Ensino Jurídico no Brasil}

Segundo Nadia de Araujo ${ }^{39}$, em 2007 foram comemorados os 180 anos de ensino jurídico no Brasil, pois da instalação dos cursos em São Paulo e Olinda, um no Sul e o outro no Norte. As escolas de direito foram as primeiras instituições de graduação a se estabelecerem, cinco anos depois da independência de Portugal, ocorrida em 1822. Nesse momento o país contava como três mil bacharéis formados na França, Inglaterra e Portugal, a maioria em Coimbra.

Uma universidade, o Brasil só veio a ter em 1920, no Rio de Janeiro, o que demonstra que também nesse aspecto o país tem uma história tardia. Atualmente o país tem 2.185 instituições de ensino superior, das quais apenas 176 são universidades. A grande maioria delas são faculdades. De todas as instituições, apenas 231 são públicas ${ }^{40}$.

As instituições de ensino superior brasileiras são submetidas a procedimentos para criação e credenciamento. Eles são realizados pela Secretaria de Educação Superior e pela Secretaria de Educação Profissional e Tecnológica e coordenados pelo Ministério de Educação, com base nos resultados de uma avaliação realizada pelo Instituto Nacional de Estudos e Pesquisas Educacionais - INEP. A criação de cursos é feita por meio de um ato legal.

O Sistema Nacional de Avaliação da Educação Superior - SINAES, instituído em 2004 redefiniu o processo de avaliação da educação superior nacional. Esse passou a ser composto de quatro instrumentos de avaliação, que são: a auto-avaliação institucional, a avaliação institucional extema, a avaliação dos cursos de graduação e os resultados do Exame Nacional de Avaliação de Desempenho dos Estudantes - ENADE, constituído por uma prova aplicada nacionalmente a alunos ingressantes e concluintes de um curso superior. Os resultados são usados como um ranking pelas escolas de direito.

O Ministério da Educação, então, é o responsável pela avaliação periódica das escolas de direito, monitorando o corpo docente, os cursos, a infra-estrutura e os horários. A cada dois anos, uma comissão especial é enviada pelo governo às instituições para acompanhar o cumprimento dos requisitos legais.

A forma de admissão do estudante na universidade é determinada por lei. Todas as instituições devem organizar um processo seletivo. $O$ tipo de processo seletivo é definido pela instituição. O método mais comum é um exame vestibular. Esse processo desempenha um papel muito importante no Brasil. Trata-se de um exame organizado pelas instituições sobre as matérias estudadas pelos alunos durante o

\footnotetext{
39 ARAUJO, Nadia de. The Status of Brazilian Legal Education. Journal of Legal Education, set./2001, p. 325-331.

${ }^{40}$ REFLEXIONES y Perspectivas de la Educación Superior en América Latina: Informe Final - Proyecto Tuning América Latina (2004-2007),p. 349
} 
ensino médio. Em função das escolas públicas serem gratuitas, os exames organizados por elas são concorridos. Por exemplo, em Porto Alegre, na minha Universidade, concorrem a cada vaga uma média de 30 candidatos. Com isso, os melhores alunos tendem a ser alunos das instituições públicas. Eles obtêm os melhores índices nos exames nacionais do final do curso e isso contribui para que as escolas públicas estejam bem posicionadas no ranking nacional.

Atualmente, a maioria das instituições públicas reserva um número específico de vagas para as chamadas quotas de afro-brasileiros, estudantes carentes ou egressos de escolas públicas de ensino médio, segundo critérios determinados por cada instituição. Os candidatos a essas quotas também devem ser aprovados em exames vestibulares.

No Brasil, estão matriculados no ensino superior 5 milhões de estudantes, o que representa 11 por cento da população entre 18 e 24 anos de idade. Concomitantemente a isso, observa-se o crescimento exponencial do número das instituições privadas.

O país possui mais de 300 mil docentes de ensino superior. Desses, apenas 65 mil possuem doutorado e apenas 110 mil possuem dedicação exclusiva para a universidade. $O$ percentual de docentes com doutorado é baixo e a modalidade de vinculação dos mesmos com a universidade, em regra, não é a dedicação exclusiva, mas sim a contratação por horas. Tal modalidade, em função da remuneração, não oferece incentivo para que os professores se dediquem à investigação e aos seus estudantes, mas sim a que tenham a atividade universitária como secundária ${ }^{41}$.

No passado, a maioria dos professores de direito eram júzes, promotores públicos ou advogados do Estado. Ter um emprego público na área do direito era um credencial para lecionar direito. Atualmente, o Brasil experimenta uma radical mudança a um quadro com professores de dedicação exclusiva e também melhor titulados. Segundo a legislação, um terço dos professores de um curso devem possuir titulação stricto sensu. Eles também estão se dedicando mais a atividades de pesquisa e a outros programas nas universidades. Os professores de uma instituição pública são selecionados após um árduo e competitivo exame. Algumas universidades somente aceitam a inscrição de doutores.

O sistema de educação superior é dividido em dois períodos acadêmicos por ano, sendo o primeiro geralmente de fevereiro a junho e o segundo de agosto a dezembro.

Não existe um sistema único, nem alguma espécie de padronização, aplicável aos créditos acadêmicos $^{42}$. Cada instituição aplica um sistema próprio, segundo os critérios estabelecidos pelos órgãos superiores da mesma. Os estudos realizados em uma instituição podem ser aproveitados em outra, mas esse processo nem sempre é pacífico.

\footnotetext{
41 Ver PÉREZ PERDOMO, Rogelio. La Profesión de Abogado y la Educación Jurídica. Revista del Colegio de Abogados del Distrito Federal. Venezuela: n. 150, tercera etapa, 1992. p. 135-152.

42 REFLEXIONES y Perspectivas de la Educación Superior en América Latina: Informe Final - Proyecto Tuning América Latina (2004-2007), p. 350
} 
Não existe um sistema único de atribuição de notas e médias necessárias para a aprovação dos estudantes. Cada instituição adota um sistema próprio.

A base da educação superior oferece cursos de graduação (bacharelado, licenciatura e tecnologia), cujas diferenças entre eles podem determinar a continuidade da carreira acadêmica ou a formação profissional, cursos de pós-graduação lato sensu e cursos de pós-graduação stricto sensu.

Os cursos de pós-graduação no país foram reestruturados no final da década de 60. A opção foi por um modelo americano que tinha o propósito de trocar o método tradicional de ensino por um método socrático, incluindo o estudo de casos nas aulas de direito. Hoje os programas de pós-graduação existentes estão crescendo e novos estão sendo implementados. Eles são direcionados para a continuidade da formação científica e acadêmica.

Cabe à Coordenação de Aperfeiçoamento de Pessoal de Nível Superior CAPES avaliá-los. A avaliação é realizada a cada três anos e as médias variam de 1 a 7. Para ser reconhecido, o curso deverá apresentar média maior que 3 . O curso de mestrado tem duração de dois anos, em média, nos quais o aluno cursa disciplinas e desenvolve uma dissertação. $O$ curso de doutorado tem uma duração de três a quatro anos, que são usados no cumprimento de disciplinas e na elaboração de uma tese.

Quanto ao ensino jurídico no Brasil, Daniel Torres de Cerqueira, presidente da Associação Brasileira de Ensino do Direito - $A B E D i^{43}$, apresenta dados sobre o número de cursos e de faculdades ${ }^{44}$. Muito é criticado o crescimento da oferta de cursos de direito no Brasil. Ele, como presidente de uma associação vinculada à área, combate essa crítica. A esse artigo aqui, só interessam os dados trazidos por ele, colhidos em consultas ao Instituto Nacional de Estudos e Pesquisas Educacionais Anísio Teixeira - INEP e ao Instituto Brasileiro de Geografia e Estatística - IBGE.

Em 2006 existiam no Brasil 1.005 cursos de direito, á incluídos os oferecidos por Universidades, Centros Universitários, Faculdades Integradas, Institutos Superiores e Faculdades isoladas, tanto públicas como privadas. Eles oferecem mais de 220 mil vagas. 650 cursos oferecem até 200 vagas e 11 oferecem mais de 1 mil vagas. A oferta é concentrada em duas regiões do país, Sul e Sudeste, que, juntas, oferecem 68 por cento dos cursos. Os cursos privados respondem por 88 por cento e os públicos pelo restante.

O estudo segue com análises sobre os anos de criação dos cursos de direito no país. Há uma desconfiança que os cursos sejam usados como moeda política. Partindo de 1827, o número teve uma leve expansão até o ano de 1900 , com a criação de mais quatro cursos, que foi uma ação estratégica do novo governo republicano que precisava

\footnotetext{
43 O papel desempenhado pela Associação na construção das novas diretrizes curriculares presentes na Resolução CNE/CES n. $9 / 2004$, bem como na discussão acerca da duração e da carga horária mínimas dos cursos de direito no Brasil pode ser acompanhado em RODRIGUES, Horácio Wanderlei. A ABEDi e as novas diretrizes curriculares para os Cursos de Direito. Anuário da ABEDi, Florianópolis, Fundação Boiteux, v. 3, n. 3, p. 53-81, 2005

44 CERQUEIRA, Daniel Torres de. O Ensino do Direito no Brasil: Breve Radiografia do Setor. $24 \mathrm{p}$
} 
contrapor os dois centros de formação mais antigos, ainda influenciados pela visão política monarquista. Em 1950 existiam 25 cursos. Em 1964 já eram 60. E desde então é observado um processo de expansão. Quando o país reabre-se para a democracia, em 1985, já existem 147. O ano de 2002 responde sozinho pela criação de 144 cursos. E hoje se tem os mais de mil mencionados. Uma análise mais detida dos dados leva à constatação que nos anos que houve eleições presidenciais, mais cursos foram criados.

Outro dado importante trazido por Cerqueira é a relação das vagas ofertadas com a demografia. Padrões usualmente utilizados no Brasil dão conta de uma relação ideal baseada na proporção de 1 vaga por 1 mil habitantes. Essa relação só não é atingida por Estados como o Amazonas, o que comprova que as regiões Sul e Sudeste possuem uma saturação de vagas.

O curso de direito é essencialmente noturno: Nesse período do dia estão 60 por cento do total das vagas. A razão disso é que normalmente os cursos não funcionam no horário do funcionamento dos fóruns. Muitos dos estudantes trabalham de forma parcial como estagiários de escritórios de advocacia ou de órgãos governamentais para sustentarem os seus estudos.

Aos alunos é exigida freqüência obrigatória de no mínimo setenta e cinco por cento das aulas. $\mathrm{O}$ ano letivo regular é de duzentos dias. Normalmente, as salas de aula têm 60 estudantes. Os estudantes raramente permanecem na instituição após as aulas.

No mérito, afirma Cerqueira que "A falência funcional diz respeito à incapacidade de nossos cursos em oferecer graduados capacitados, dentro de uma premissa tradicional, de atuarem nas diversas esferas profissionais. Prova disso é a enorme quantidade de egressos que não passam nos exames da Ordem dos Advogados do Brasil e o baixo índice de aprovação nos concursos públicos para a magistratura e para a promotoria pública. Já a falência sistêmica diz respeito à incapacidade dos cursos de direito do Brasil em formarem bacharéis capacitados a analisarem o direito à luz dos novos fenômenos sócio-políticos, como é o caso da globalização, da atuação dos movimentos sociais ou na esfera de defesa dos assim chamados direitos difusos" ${ }^{45}$.

Por fim, cabe ser dito que o direito brasileiro segue o sistema da civil law. Em verdade, toda a América Latina é herdeira da ideologia da codificação. As diretrizes jurídicas transpostas para as colônias da América luso-hispânica provêm de fontes históricas romano-germanas e da adequação da herança normativa institucional da colonização ibérica. Seria lógico pensar em uma harmonização do ensino jurídico no Continente em função dessa origem comum e da filiação ao sistema da civil law ${ }^{46}$. Todavia, tal não ocorre e não ocorrerá logo.

\footnotetext{
${ }^{45}$ CERQUEIRA, Daniel Torres de. O Ensino do Direito no Brasil: Breve Radiografia do Setor. $24 \mathrm{p}$.

46 PEÑA GONZÁLEZ, Carlos. Características y Desafíos de la Enseñanza Legal Latinoamericana. 7 p. Disponível em: http:// www.aals.org/2000international/. Acesso em 15.11.2007.
} 


\section{Considerações finais}

Em sede de considerações finais, vejam-se os motivos do insucesso das experiências latino-americanas até agora tentadas:

1. O Processo de Bolonha se tomou conhecido no meio acadêmico latino-americano e instigou iniciativas para um projeto similar. Os estudos iniciais foram desenvolvidos no Continente pelo Projeto Tuning América Latina. O levantamento de informações sobre os sistemas de educação abrangeu o direito. As idéias de reconhecimento de títulos e de mobilidade de estudantes e profissionais são sempre aceitas com simpatia e expectativa por milhares de brasileiros fronteiriços, por exemplo, que se dirigem cada vez mais a países vizinhos para realizarem seus cursos e esperam um dia vê-los reconhecidos, bem como por diversos grupos de interessados.

2. Os resultados do Projeto Tuning América Latina representam uma informação confiável e objetiva sobre a educação no Continente. No caso do ensino do direito, os resultados conduzem à necessidade de modificações.

3. Aproximação por competências, harmonização de sistemas educativos, compatibilidade de titulações e mobilidade de profissionais e estudantes de direito parece ser um desejo não facilmente atingível. Os processos de integração desenvolvidos na América Latina, que poderiam se ocupar desses objetivos, se dedicam, por ora, a aspectos unicamente econômicos e nenhum deles têm um mercado comum desenvolvido a exemplo da integração européia. Em verdade, são integrados por países que durante muito tempo viveram de costas para os outros, muito raramente compartilharam experiências jurídicas e hoje apresentam todas as formas de obstáculos para harmonizações legislativas. Lembre-se que o fato do direito brasileiro ser originário de Portugal dificultou historicamente a aproximação legislativa com os demais países do continente, de colonização espanhola.

4. Além disso, as realidades nacionais do ensino do direito são distantes. Há uma série de diferenças quanto à duração dos cursos, carga horária mínima, obrigatoriedade de freqüência dos estudantes, exigência de trabalhos finais, heterogeneidade dos currículos e, quanto à questão profissional, diferenças expressivas nos critérios adotados para a habilitação dos advogados. O direito é um dos cursos mais antigos no espaço educacional latino-americano. Ele conta com uma larga história quanto à organização do seu currículo, metodologia de ensino, objetivos de aprendizagem, formação de docentes. Isso em muitas situações se contrapõe a um modelo de formação por competências.

5. O Brasil, por exemplo, uma das grandes nações do Continente, experimentou regras rígidas, mas vem flexibilizando as diretrizes para o ensino do direito. O resultado é uma maior liberdade das universidades para a elaboração de currículos. Esforços de flexibilização, apoio à inovação nos currículos, propostas de atualização dos currículos para as sociedades multiculturais ${ }^{47}$

47 OLIVEIRA JÚNIOR, José Alcebíades de. Repensando o ensino do Direito para sociedades multiculturais - da Pedagogia ao currículo. Revista da Faculdade de Direito da Universidade Federal do Rio Grande do Sul. Porto Alegre: Sulina, v. 25, dez./05, p 109-120. 
e propostas de novos currículos que promovam rupturas com sistemas tradicionais ${ }^{48}$ implicam em dificuldades de harmonização dos mesmos. Propostas de adequação dos cursos à realidade mundial globalizada e culturalmente diversificada - grupal e individualmente ${ }^{49} \mathrm{y}$ às demandas contemporâneas das profissões jurídicas também se mostram como contrapontos a um currículo harmonizado no continente. Acredita-se, inclusive, que no futuro as faculdades de direito tenderão a diferenciar-se entre si pela capacidade que tenham de flexibilizar os seus currículos ${ }^{50}$.

6. Em outros países, e também no Brasil em alguns aspectos, o poder do Estado na regulação do ensino é amplo e a sua manutenção dificulta uma harmonização de sistemas educativos. $O$ Estado controla o ensino desde o processo de autorização e reconhecimento de uma instituição, credenciamento de cursos, adequação às diretrizes curriculares dos cursos, implantação e execução do processo de avaliação, até o reconhecimento de títulos obtidos no exterior.

7. Por fim, a manutenção do nível da formação profissional que o Brasil atingiu com a implantação da obrigatoriedade de um Exame fora da universidade, sem a administração dessa, promovido pela Ordem dos Advogados do Brasil, no que é único na América Latina, resguardadas as proporções, pode ser um argumento comparável aquele de setores da Alemanha que questionam o Processo de Bolonha, fundados na manutenção do seu sistema de formação de um jurista único Einheitsjurist ${ }^{51}$, entendido como aquele profissional formado para o exercício de todas as profissões jurídicas, após a satisfação do Segundo Exame do Estado. A Alemanha não quer perder esse nível completo de formação que esse fenômeno da separação entre ensino e exame implica em seus estudantes, fazendo com que eles tenham que percorrer a mesma educação independentemente da profissão jurídica clássica que ele queira desempenhar, possuir o mesmo conhecimento sobre a legislação alemã e sobre o sistema jurídico alemão. $\mathrm{O}$ Brasil certamente não desejará abrir mão do seu Exame da Ordem, em breve, em favor de uma harmonização.

\footnotetext{
48 VANZELLA, Rafael Domingos Faiardo (org). Experiências e Materiais sobre os Métodos de Ensino-Aprendizado da Direito GV. São Paulo: Fundação Getilio Vargas, 2007.p. 7-23.

49 OLIVEIRA JÚNIOR, José Alcebíades de. Repensando o ensino do Direito para sociedades multiculturais -- da Pedagogia ao currículo. Revista da Faculdade de Direito da Universidade Federal do Rio Grande do Sul. Porto Alegre: Sulina, v. 25, dez. / 05, p. 109-120

50 PEÑA GONZÁLEZ, Carlos. Características y Desafíos de la Enseñanza Legal Latinoamericana. 7 p. Disponível em: http:/ /www.aals.org/2000intemational/. Acesso em 15.11.2007.

51 KEILMANN, Annette. The Einheitsjurist: A German Phenomenon, in: German Law Journal, Vol. 07, No. 03 (1 March 2006), page 293-312.
} 